\title{
Dual Pseudo- and Chemical Crosslinked Polymer Micelles for Effective Paclitaxel Delivery and Release
}

\author{
Xiaotong Song, Ke Yuan, Hongyan Li, Shoufang Xu*, Yinwen Li* \\ School of Materials Science and Engineering, Linyi University, Linyi 276000, People's \\ Republic of China.
}

Corresponding Author

*E-mail: liyinwen06@126.com

*E-mail: xshfang1981@163.com 


\section{Synthesis of 2-methoxyethyl 2-bromoisobutyrate (MBIB)}

MBIB was prepared by reaction between 2-methoxyethanol and 2-bromoisobutyryl bromide (BIBB). Basically, dissolved ethylene glycol monomethyl ether (3.04 g) and triethylamine $(6.07 \mathrm{~g})$ in anhydrous diethyl ether $(200 \mathrm{~mL})$ and cooled below $0{ }^{\circ} \mathrm{C}$, then added BIBB $(18.4 \mathrm{~g})$ dropwise for about $4 \mathrm{~h}$ and stirred for $48 \mathrm{~h}$ at room temperature. The obtained mixture was filtrated, washed with $\mathrm{HCl}$ aqueous solution, brine and water for three times, respectively. The organic phase was separated and dried over anhydrous $\mathrm{MgSO}_{4}$, then concentrated and purified by column chromatography (ethyl acetate/hexane, $1: 4 / \mathrm{v}: \mathrm{v}$ ), yield $\approx 72 \% .{ }^{1} \mathrm{H}$ NMR (400 MHz, $\left.\mathrm{CDCl}_{3}\right): \delta(\mathrm{ppm}) 4.29\left(2 \mathrm{H},-\mathrm{CH}_{2} \mathrm{COO}-\right), 3.64\left(2 \mathrm{H}, \mathrm{CH}_{3} \mathrm{OCH}_{2^{-}}\right), 3.39\left(3 \mathrm{H}, \mathrm{CH}_{3} \mathrm{O}-\right)$, $1.97\left(6 \mathrm{H},-\mathrm{C}\left(\mathrm{CH}_{3}\right)_{2}\right)$.

\section{Synthesis of PGMA}

The reactor purged with high purified nitrogen, and diphenyl ether $(5.0 \mathrm{~mL}), \mathrm{MIBB}(1 \mathrm{mmol})$, GMA (41 mmol), and $\mathrm{CuBr}(1 \mathrm{mmol})$ were added and degassed via three freeze-thaw-pump cycles, then added PMDETA (2 mmol) and the reactor was immediately immersed in a preheated oil bath at $20{ }^{\circ} \mathrm{C}$ for $30 \mathrm{~min}$, then stopped the polymerization immediately by immersing the reactor into liquid nitrogen and exposing to air. The resultant viscous product was diluted with DCM and divided through neutral alumina column. The collected liquid was subsequently precipitated by excessive hexane, and freeze-dried under vacuum for $24 \mathrm{~h}$ to finally obtain the $\mathrm{PGMA}_{40}$ (yield $\approx 94.7 \%$ ). ${ }^{1} \mathrm{H}$ NMR (400 MHz, $\left.\mathrm{CDCl}_{3}\right): \delta(\mathrm{ppm}) 3.79,4.30$ (- $\left.\mathrm{COOCH}_{2^{-}}\right), 3.53\left(\mathrm{CH}_{3} \mathrm{OCH}_{2^{-}}\right), 3.38\left(\mathrm{CH}_{3} \mathrm{O}-\right), 3.23$ (- $\mathrm{CH}_{2} \mathrm{OCH}-$, epoxy group), 2.63, 2.84 (- $\mathrm{CH}_{2} \mathrm{OCH}-$, epoxy group), $1.69 \sim 2.05 \quad\left(-\mathrm{C}\left(\mathrm{CH}_{3}\right) \mathrm{CH}_{2^{-}}\right), \quad\left(-\mathrm{OOCC}\left(\mathrm{CH}_{3}\right)_{2}-\right), \quad 0.76-1.20$ $\left(-\mathrm{C}\left(\mathrm{CH}_{3}\right) \mathrm{CH}_{2-}\right)$. 
A

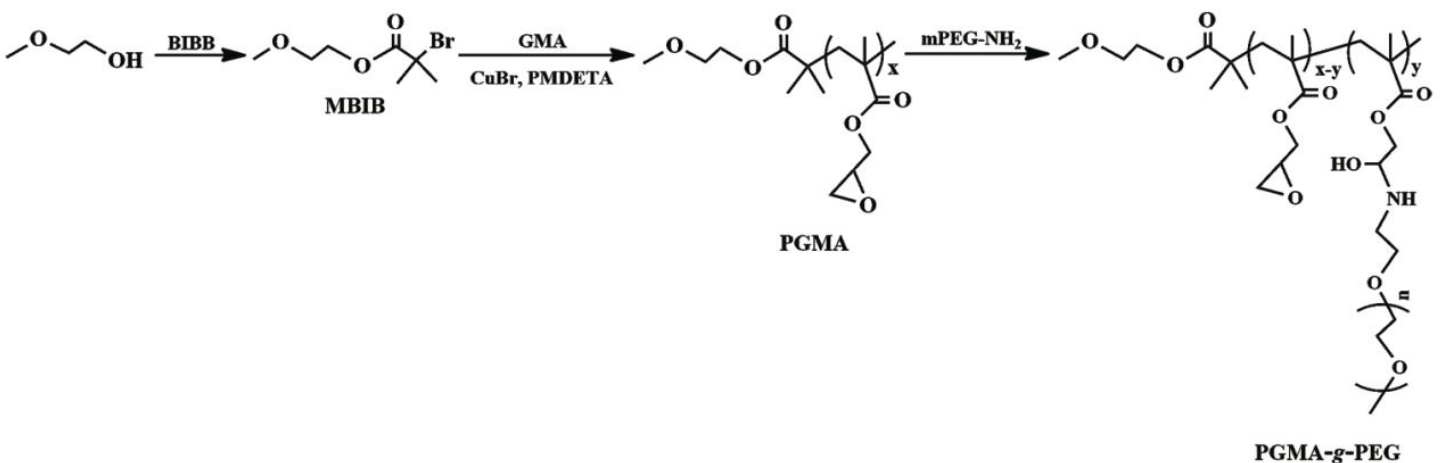

B

PGMA

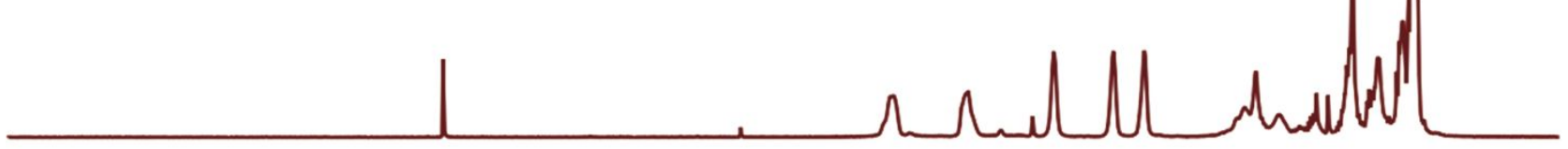

MBIB

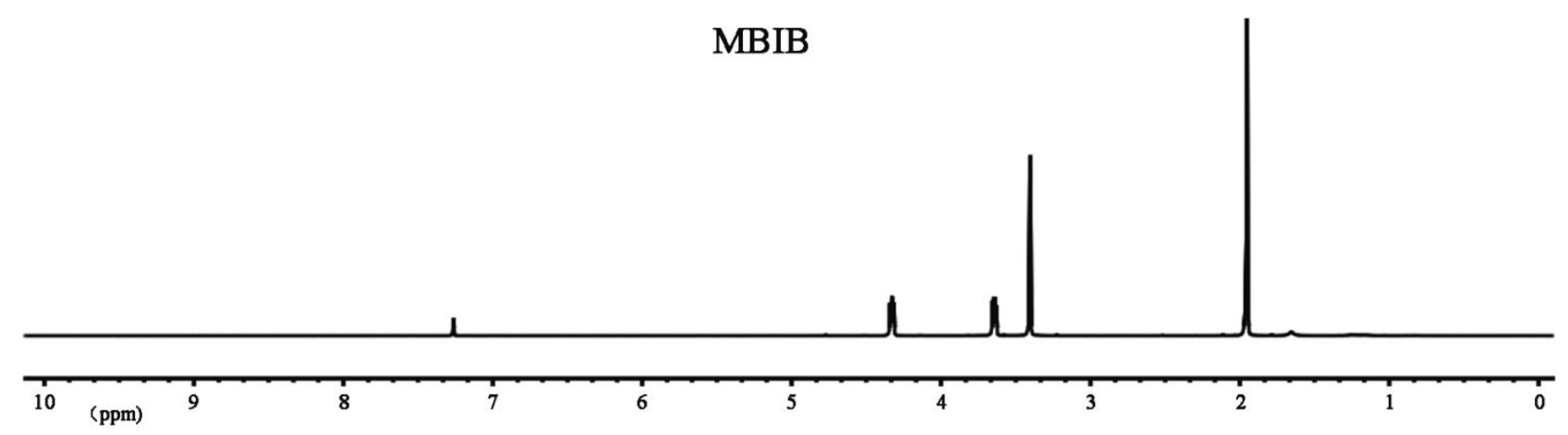

Figure S1. The synthetic routes of PGMA-g-PEG (A) and the ${ }^{1} \mathrm{H}$ NMR spectra of MBIB and PGMA (B). 


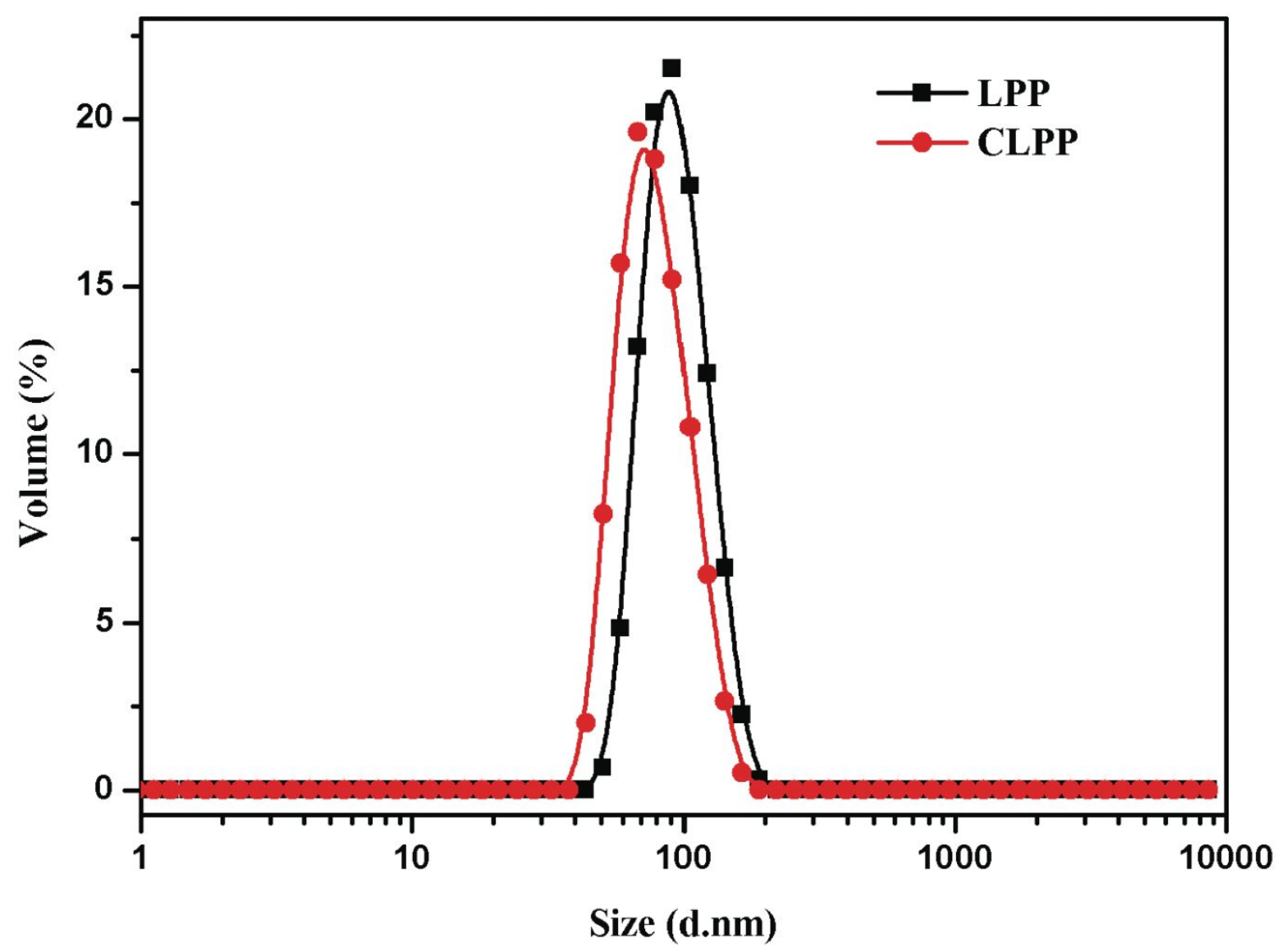

Figure S2. The volume sizes of polymer micelles (LPP) prepared from linear PGMA-g-PEG and cystamine crosslinked polymer micelles (CLPP) with the $M_{\text {epoxy }}: M_{\text {cystamine }}$ equal to $1: 1$. 


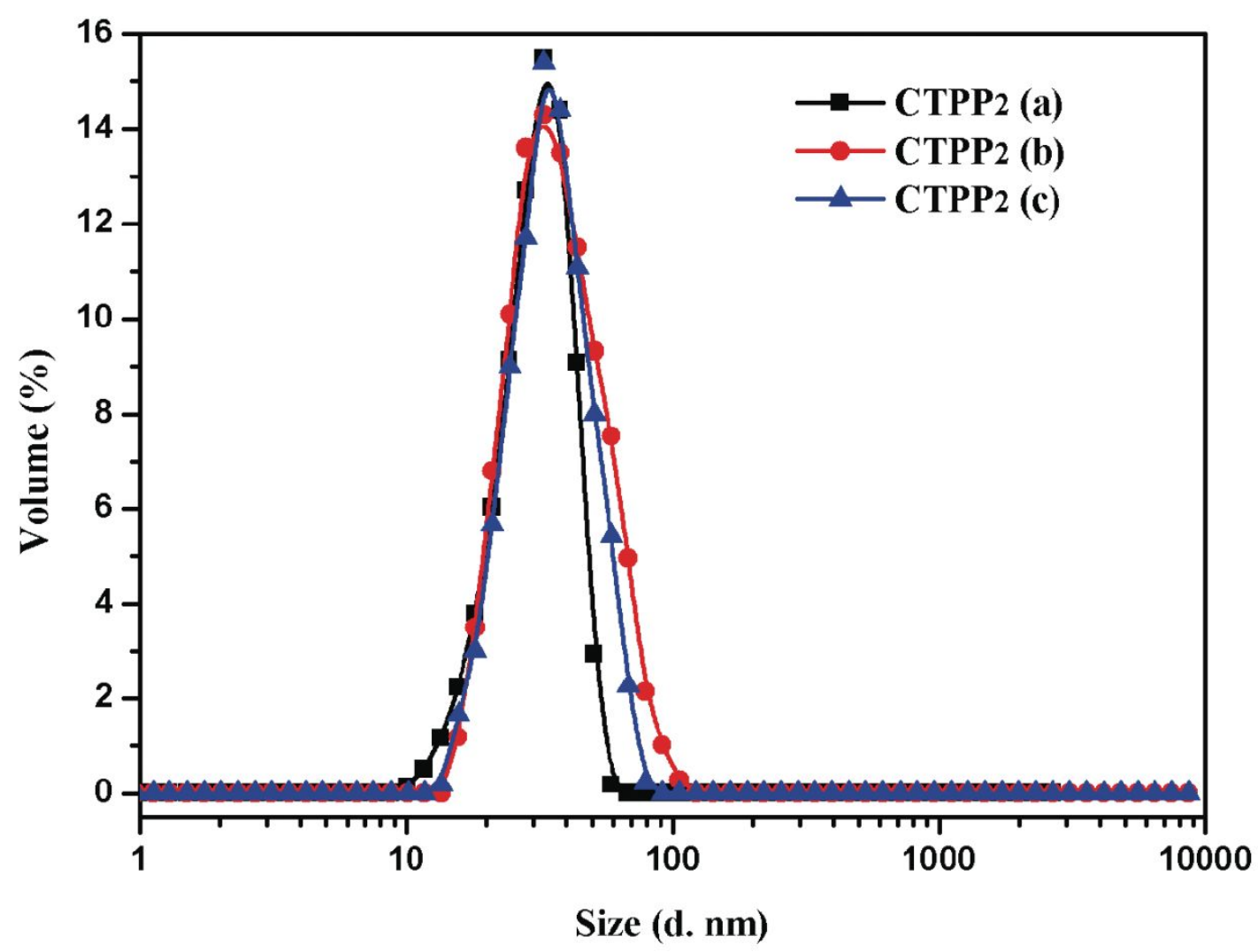

Figure S3. The volume sizes of cystamine crosslinked $\operatorname{TPP}_{2}\left(\mathrm{CTPP}_{2}(\mathrm{a}), \mathrm{CTPP}_{2}(\mathrm{~b})\right.$, and $\left.\mathrm{CTPP}_{2}(\mathrm{c})\right)$ prepared by TMP-PGMA $40-g-\mathrm{PEG}_{10}$ with the $M_{\text {epoxy }}: M_{\text {cystamine }}$ equal to $2: 1,1: 1$, $1: 2$, respectively. 


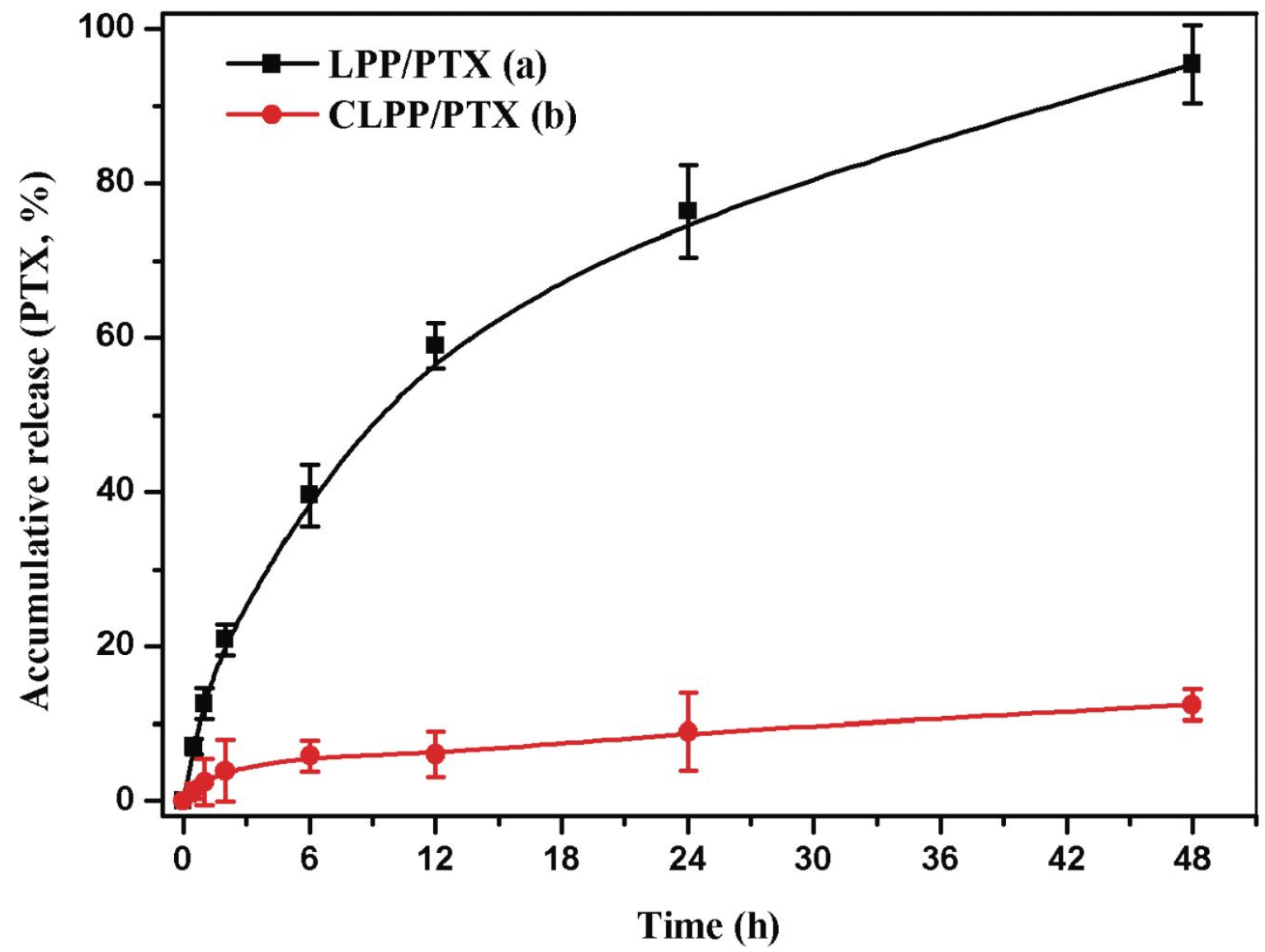

Figure S4. The accumulative release amounts of PTX from LPP/PTX (a) and CLPP/PTX (b) measured by HPLC. 


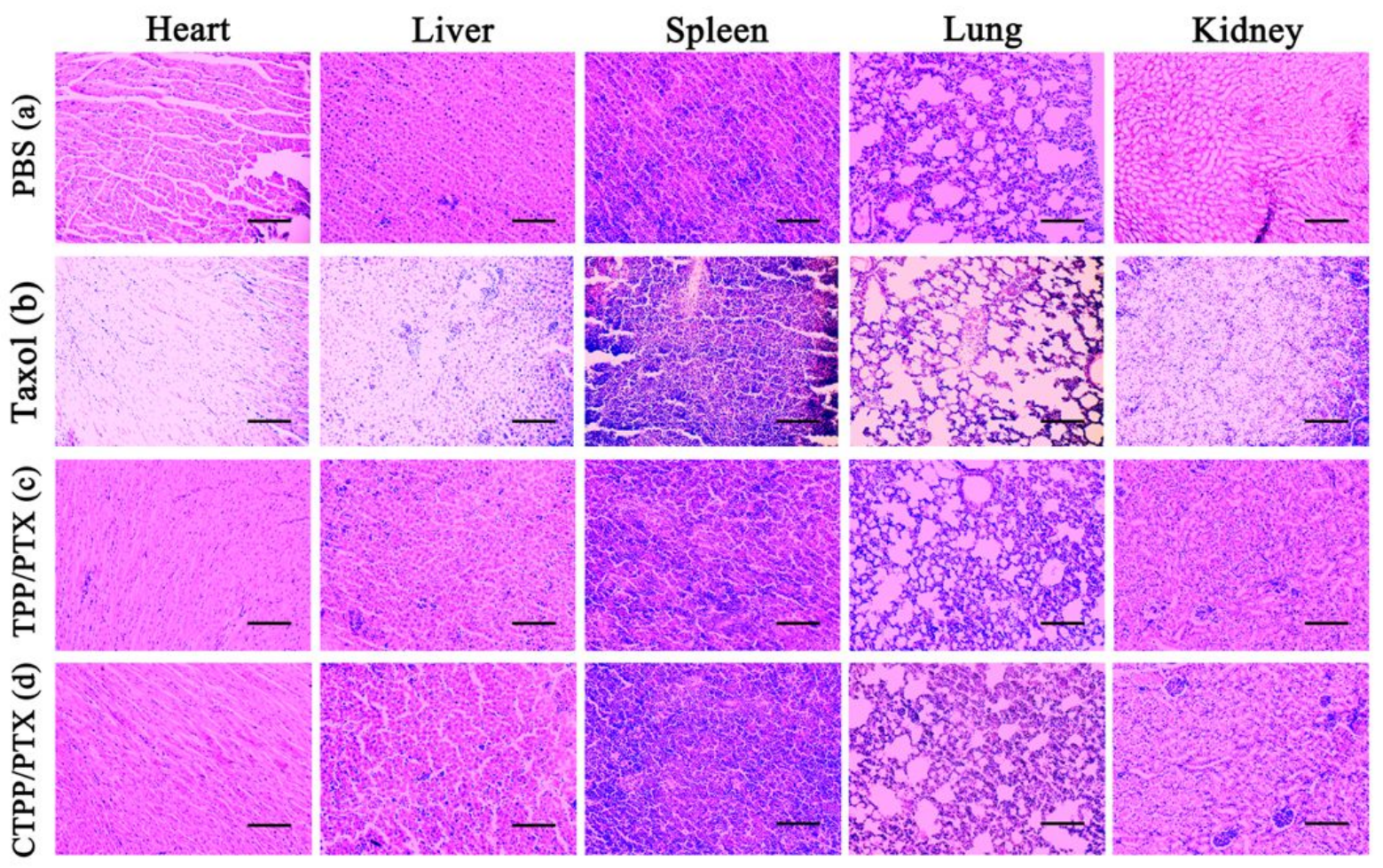

Figure S5. The mice organs (heart, liver, spleen, lung, and kidney) paraffin sections treated with PBS (a), Taxol (b), TPP/PTX (c), CTPP/PTX (d) and stained with hematoxylin-eosin (H\&E) and histopathologic analysis (magnification $\times 20$, and with scale bar about $100 \mu \mathrm{m}$ ). 